Research Article

\title{
Fractional Order Linear ADRC-Based Controller Design for Heat-Flow Experiment
}

\author{
Ubaid M. Al-Saggaf $\left(\mathbb{D},{ }^{1,2}\right.$ Ibrahim M. Mehedi ${ }^{(D)}{ }^{1,2}$ Rachid Mansouri $(\mathbb{D})^{3}$ \\ and Maamar Bettayeb ${ }^{2,4}$ \\ ${ }^{1}$ Department of Electrical and Computer Engineering (ECE), King Abdulaziz University, Jeddah 21589, Saudi Arabia \\ ${ }^{2}$ Center of Excellence in Intelligent Engineering Systems (CEIES), King Abdulaziz University, Jeddah 21589, Saudi Arabia \\ ${ }^{3}$ Laboratoire de Conception et Conduite des Systemes de Production (L2CSP), Tizi-Ouzou, Algeria \\ ${ }^{4}$ Electrical Engineering Department, University of Sharjah, Sharjah, UAE
}

Correspondence should be addressed to Ibrahim M. Mehedi; imehedi@kau.edu.sa

Received 27 May 2021; Revised 2 June 2021; Accepted 6 June 2021; Published 29 June 2021

Academic Editor: Dr. Dilbag Singh

Copyright (C) 2021 Ubaid M. Al-Saggaf et al. This is an open access article distributed under the Creative Commons Attribution License, which permits unrestricted use, distribution, and reproduction in any medium, provided the original work is properly cited.

\begin{abstract}
Fractional order control (FOC) has received widespread attention in recent years due to its efficient tuning capacity, intuitive concept, and enough flexibility. Again, FOC are known to be robust with the open loop gain in particular. However, the design of FOC demands the knowledge of the model to be modified. But on the other hand, the linear active disturbance control (LADRC) technique is known to be model free controller. In order to achieve the better tracking performance even in uncertain operational conditions by responding timely against external disturbances, these two controllers (FOC and LADRC) are combined to propose a new fractional order LADRC to handle integer order system. Therefore, FOC-based LADRC for heat-flow experiment (HFE) is designed in this paper to track desired trajectories of heat flow. Bode's ideal transfer function is considered as an orientation model to propose this new controller while using the concept of internal mode control. A better performance of fractional order linear active disturbance control (FO-LADRC) is shown for a very good disturbance rejection capability through simulation and experiments on a heat-flow system.
\end{abstract}

\section{Introduction}

A great advance in modern control theories has occurred leading to the development of a vast number of new control techniques in the recent past decades. Despite the large number of newly available controllers, the proportionalintegral-derivative (PID) controller is still preferred in various manufacturing applications. The chief reason behind this is the fact that the structure of the PID is simple and hence easily understandable by engineers and easy to design and implement. Also, the PID performs successfully for a wide class of processes.

Linear active disturbance rejection control (LADRC) is the latest version of error-driven control leading PID controller [1]. It does not need accurate model in prior. The actual input-output parameters are analyzed to recompense unpredictable disturbances and uncertainties [2]. Due to this compensating ability, LADRC produces better tracking performance even in uncertain operational conditions by responding timely against external disturbances. Therefore, set-point tracking and disturbance rejection both are executable by the LADRC technique [3]. LADRC is being applied both in academic research and industrial process control because of its simple structure and ease of tuning capacity.

In the last few years, increasing attention has been given toward improving the outcomes of LADRC regulators by implementing the idea of fractional calculus which has been generalized as fractional order LADR controller (FOLADRC). FO-LADRC offers more tractability because of its better parameters over standalone LADRC, because a fractional order controller or an integer order controller 
demands the knowledge about the system model to be modified. But on the other hand, the linear active disturbance control (LADRC) technique is known to be model free controller. Therefore, to enhance the robustness of the LADRC technique, it is beneficial to incorporate with the fractional order controller.

To explore new applications, a new tuning method of FO-LADRC is accomplished in this research. Earlier, fractional order controllers are tuned based on PID controller in several investigations (see for example $[4,5]$ and references therein for more knowledge). More researches are conducted to develop new tuning techniques and to demonstrate PID cascaded FO controllers [6-12].

In these works, a new control structure is developed to rheostat fractional or integer order systems with and without small time delay. The anticipated regulator consists of dual transfer functions: one is for time-delay-free systems in which an LADRC controller is cascaded with a fractional integrator and a simple fractional filter. This new structure having several important advantages such as fractional order filter LADR controller is easy to design and implement. Also, a number of industrial systems can be controlled by it. Using fractional filter, the performance of LADRC will be more robust.

Although various modern controllers have been designed for regulating temperature using process control strategies, this paper attempts to apply the FO-LADRC controllers for integer order systems in a laboratory experiment. The heat-flow experiment (HFE) platform is used for this experiment. Fractional LADRC principle-based controller is designed for a well-known Bode's ideal reference transfer function.

In fact, two different temperature sensors are used for two different purposes in this delayed time heat-flow experiment. One sensor is used to measure the temperature as the output of feedback control and other sensor is used to measure the temperature to be controlled. This feature can not be solved well using standard control schemes based on the model of the system to be controlled. Therefore, a new robust LADRC scheme is proposed in this paper for the time-delay heat-flow experiment.

The rest of the paper is organized as follows: an outline of heat-flow experiment (HFE) is discussed in Section 2. The design procedure of the proposed LADRC is explained in Section 3. Section 4 shows the experimental results varying different parameters and discusses the effectiveness of the proposed scheme. Finally, Section 5 concludes the current investigation.

\section{HFE System}

The heat-flow experiment (HFE) device demonstrated by Quanser helps in investigating the heat transmission in a chamber as well as controlling of temperature at particular places along the chamber $[13,14]$. This progression regulation plant is best for coaching, learning, and representing perceptions of control related to thermodynamics and fluid dynamics.
The HFE delivered by Quanser is shown in Figure 1. This progression rheostat plant is made of a fiberglass compartment which comprehends a blower and a coil-based heating apparatus at one side and three temperature sensors equidistantly situated along the conduit. Power is delivered to the blower and heater using a built-in amplifier. Analog signals are used to control the delivered power. A tachometer is mounted on the blower and is used to measure the blower's angular rate. Fast-settling platinum transducers are used for all three temperature sensors in the chamber. The sensor produces analog voltage signal from zero to 5.0 volts as output which is proportional to the temperature. An information procurement called data acquisition (DAQ) board is utilized in addition to the process control plant in this experiment.

In the duct, three temperature sensors are located equidistantly to measure the heat-flow performance. The sensors are actually fast-settling platinum transducers. Using model-based standard controller, the position of the controller is linked to the time delay of the first order model $[13,14]$. By using model free controller, such as LADRC, the position of the sensors (or time delay) included in the proposed model is explained in the following section.

\section{Controllers Design Procedure}

3.1. Bode's Ideal Transfer Function. A fractional order controller design imposes on the closed-loop feature based only on the noninteger order in which it was introduced. In this case, this feature will be robust relative to the variations of the system parameters. To achieve this goal, one solution is to impose on the open loop a behavior similar to that of Bode's ITF [15-17]. So, the phase margin will be constant and, therefore, the overshoot of the closed-loop step response does not change with the variations of the static gain of the system to be controlled.

The ITF suggested by Bode [18] is

$$
G_{\mathrm{ol}}(s)=\frac{\omega_{c}}{s^{\mu}}, \quad \mu \in \mathbb{R}^{+} .
$$

The Bode's ITF in closed-loop is then

$$
G_{\mathrm{cl}}(s)=\frac{\omega_{c}}{s^{\mu}+\omega_{c}} \text {. }
$$

Its step response exhibits the so-called iso-damping property. In this paper, $G_{\mathrm{cl}}(s)$ is used as a closed-loop reference model to tune the control law parameters. It has two adjustable parameters, the controller bandwidth $\omega_{c}$ and the fractional order $\mu$, which can be deduced from the phase $\operatorname{margin} \varphi_{m}$ by $\mu=\left(\pi-\varphi_{m}\right) /(\pi / 2)[15,16]$.

3.2. Integer Order Linear ADRC. Figure 2 shows an integer order LADRC structure. Usually, the HFE system is demonstrated by a 1st order with time-delay model [19]. In this paper, in order to use the ADRC structure, we propose to model it by the differential equation:

$$
\ddot{y}(t)=b_{0} u(t)+f(t),
$$




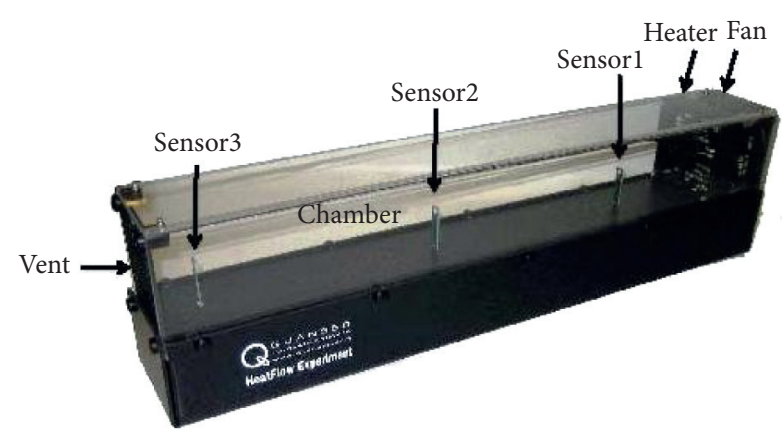

Figure 1: Heat-flow experimental device.

where $u(t)$ is the control voltage of the heather and $y(t)$ is the temperature in the chamber of the HFE system; $b_{0}$ is the estimate value of the system gain; and $f(t)$ is an unknown function representing unknown and unmodelable dynamics and external disturbances. For the HFE system, $f(t)$ also contains the nonmodeling error of the system delay. $f(t)$ is called the generalized disturbance.

In the ADRC framework, the unknown generalized disturbance $f(t)$, assumed to be differentiable, is estimated using the IESO [20-22] (Figure 2).

$$
\left\{\begin{array}{l}
\dot{z}=A z+B u+L\left(y-y_{o}\right), \\
y_{o}=C z,
\end{array}\right.
$$

where $z=\left[\begin{array}{lll}y & \dot{y} & f\end{array}\right]$,

$$
\begin{aligned}
& A=\left[\begin{array}{lll}
0 & 1 & 0 \\
0 & 0 & 1 \\
0 & 0 & 0
\end{array}\right], \\
& B=\left[\begin{array}{c}
0 \\
b_{0} \\
0
\end{array}\right], \\
& C=\left[\begin{array}{lll}
1 & 0 & 0
\end{array}\right],
\end{aligned}
$$

and $L=\left[\begin{array}{lll}\beta_{1} & \beta_{2} & \beta_{3}\end{array}\right]^{T}$ is the gain vector of the observer. Parameters $\beta_{1}, \beta_{2}$, and $\beta_{3}$ are tuned so that $(A-\mathrm{LC})$ is Hurwitz. In this case, $z_{1}(t)$ and $z_{2}(t)$ approximate $y(t)$ and $\dot{y}(t)$, and $z_{3}(t)$ approximates the unknown generalized disturbance $f(t)$. $L$ is designed using the observer bandwidth $\omega_{o}$, as suggested in [23]. It is given by

$$
L=\left[\begin{array}{lll}
3 \omega_{o 1} & 3 \omega_{o 1}^{2} & \omega_{o 1}^{3}
\end{array}\right]^{T} .
$$

To reject $f(t)$, the following control law is used [22]:

$$
u=\frac{-z_{3}+u_{0}}{b_{0}} \text {. }
$$

If the estimated error is ignored, $\left(z_{3}(t)=f(t)\right)$ is assumed, then the original model equation (3) is reduced to the second order integral model

$$
\ddot{y}(t)=u_{0}(t),
$$

for which set-point tracking is solved using a state feedback method. So, the control law $u_{0}(t)$ is given by

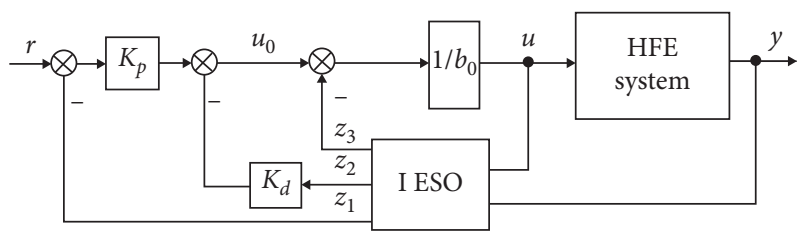

FIGURE 2: Integer order LADRC scheme.

$$
u_{0}=k_{p}(r-y)-k_{d} z_{2}
$$

Considering equations (8) and (9), the closed-loop transfer function will be

$$
G_{r y}(s)=\frac{k_{p}}{s^{2}+k_{d} s+k_{p}}=\frac{\omega_{c}^{2}}{\left(s+\omega_{c}\right)^{2}} .
$$

Parameters $k_{p}$ and $k_{d}$ are designed using the adjustment controller bandwidth $\omega_{c}$ as

$$
\begin{aligned}
& k_{d}=2 \omega_{c 1}, \\
& k_{p}=\omega_{c 1}^{2} .
\end{aligned}
$$

3.3. Fractional Order LADRC. The HFE system is modeled as a fractional order controller by using the ADRC structure

$$
D^{2 \lambda} y(t)=b_{0} u(t)+f_{1}(t) \quad 0<\lambda<1 .
$$

Suppose that $f_{1}(t)$ is differentiable and consider the state variables: $x=\left[\begin{array}{ll}y & f_{1}\end{array}\right]^{T}$. To estimate $f_{1}(t)$, the following FESO is used

$$
\left\{\begin{array}{l}
D^{2 \lambda} z=A z+B u+L\left(y-y_{o}\right), \\
y_{o}=C z
\end{array}\right.
$$

where

$$
\begin{aligned}
& A=\left[\begin{array}{ll}
0 & 1 \\
0 & 0
\end{array}\right], \\
& B=\left[\begin{array}{l}
b_{0} \\
0
\end{array}\right], \\
& E=\left[\begin{array}{l}
0 \\
1
\end{array}\right], \\
& C=\left[\begin{array}{ll}
1 & 0
\end{array}\right],
\end{aligned}
$$

and $L=\left[\begin{array}{ll}\beta_{1} & \beta_{2}\end{array}\right]^{T}$ is the gain of the observer to be determined. The corresponding characteristic polynomial is then

$$
s^{4 \lambda}+\beta_{1} s^{2 \lambda}+\beta_{2} \text {. }
$$

Therefore, to ensure the convergence of the observer, $\beta_{1}$ and $\beta_{2}$ are calculated so that the roots of the integer order polynomial corresponding to the polynomial equation (15) by the change of variable $w=s^{2 \lambda}$ satisfy the Matignon's stability condition [24]. Here also, the method proposed in [23] is used.

$$
L=\left[\begin{array}{ll}
2 \omega_{o 1} & \omega_{o 1}^{2}
\end{array}\right],
$$


where $\omega_{o 1}$ is the observer bandwidth in the $w$ plan.

The association of FESO equation (13) with the model equation (12), using the control law equation (17), yields to the fractional integrator of order $2 \lambda$.

$$
u=\frac{-z_{3}+u_{0}}{b_{0}} \text {. }
$$

The new input $u_{0}(t)$ is now used to solve the set-point tracking problem. To make the control structure even more robust, the Bode's ITF equation (2) is chosen as reference to the closed-loop transfer function. To do this, the following control law is used:

$$
u_{0}=k_{c}(r-y)
$$

In this case, the closed-loop transfer function is

$$
G_{r y}(s)=\frac{k_{c}}{s^{2 \lambda}+k_{c}}==\frac{\omega_{c}}{s^{2 \lambda}+\omega_{c}} .
$$

Parameters $k_{c}$ and $\lambda$ are given by

$$
\begin{gathered}
\lambda=\frac{\mu}{2}, \\
k_{c}=\omega_{c},
\end{gathered}
$$

where $\omega_{c}$ is the controller bandwidth in the $w$-plan and $\mu$ is the fractional order of the Bode's ideal transfer function equation (1). Figure 3 shows the fractional order LADRC structure obtained.

\section{Experimental Results}

Figure 4 shows the experimental setup. The HFE, DAQ board, and personal computer are shown in the figure as hardware components. The real-time experiment is conducted using MATLAB and QUARC software of version 2.6. DAQ board processes the sensor signals from HFE to the controller.

The experimental results of integer order LADRC are found by using a square reference input of maximum amplitude 40 and minimum amplitude 35, as shown in Figure 5. It shows the impact of varying closed-loop pole position, $\omega_{c}$, for integer order LADRC controller. Using this experiment, the best value of closed-loop pole position, $\omega_{c}$, is chosen as 0.88 . Initially, the temperature rises slowly while $\omega_{c}$ is close enough to the origin, as shown in Figure 5. Again, the constant 6.0 volts is applied to the blower to run it at a constant rate. On the other hand, the temperature set-point is maintained through the control voltage to the heater which is up to 5.0 volts. Sensor 1 is chosen to measure the temperature in the chamber for this experiment. This sensor transfers the feedback signal to the controller to regulate the temperature. However, one can select whichever sensor $(1,2$, or 3 ) to control. Initial ambient temperature, $27^{0}$ to $28^{0}$, is upheld during the experimentation. To regain the normal temperature of the chamber, the scheme is kept in relaxation till the temperature of the heating coil is reduced after each run. All the results are plotted for desired and measured temperatures along with real-time voltages for the heater and blower.

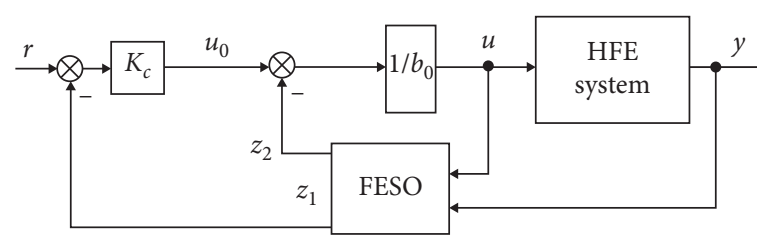

FIgure 3: Fractional order LADRC scheme.



Figure 4: Experimental setup of HFE.

The experimental results of fractional order LADRC (FO-LADRC) are obtained using a square set-point input of maximum amplitude 40 and minimum amplitude 35 , as shown in Figure 6. 5.0 volts is applied as control voltage to the heater in order to regulate the temperature around the set-point. Applying constant 6.0 volts, the blower was being run at the same rate. For these results, sensor 1 is used to produce the feedback command for the controller to control the temperature of it. $25^{0}$ to $30^{\circ}$ is maintained throughout the experiments as initial ambient temperature.

The performance of the proposed controller is observed while applying three values of $\lambda(\lambda=0.46, \lambda=0.48$, and $\lambda=0.51$ ), as shown in Figure 6. In this figure, it is shown that the overshoot increases due to increased value of $\lambda$ consequently; the control voltage requirement becomes higher than the maximum permissible value.

Figure 7 displays the temperature restrained on sensor 1 and the control input for all controllers and for the three values of closed-loop pole position $(0.15,0.17$, and 0.2$)$. Note that for large values of closed-loop pole position, the overshoot of the response becomes smaller. Figure 8 shows an experimental comparison between fractional order and integer order LADRC controller for sensor 1. Performance comparison is shown in Table 1 for different experiments conducted for different values of $\lambda$ and $\omega_{c}$.

Note that the performance of FO-LADRC is better than ILADRC and the voltage required for the fractional order controller is lower than that of the integer order controller. Further, the frequency of input voltage required by ILADRC is higher than that of FO-LADRC, as shown in Figures 5-9.

To show the robustness of the proposed fractional order LADRC controller, the same experiment is conducted, but the feedback signal is that measured by sensor 3 and the controlled temperature is that on sensor 1. Figure 9 shows the temperature restrained on sensor 1 and the control input 

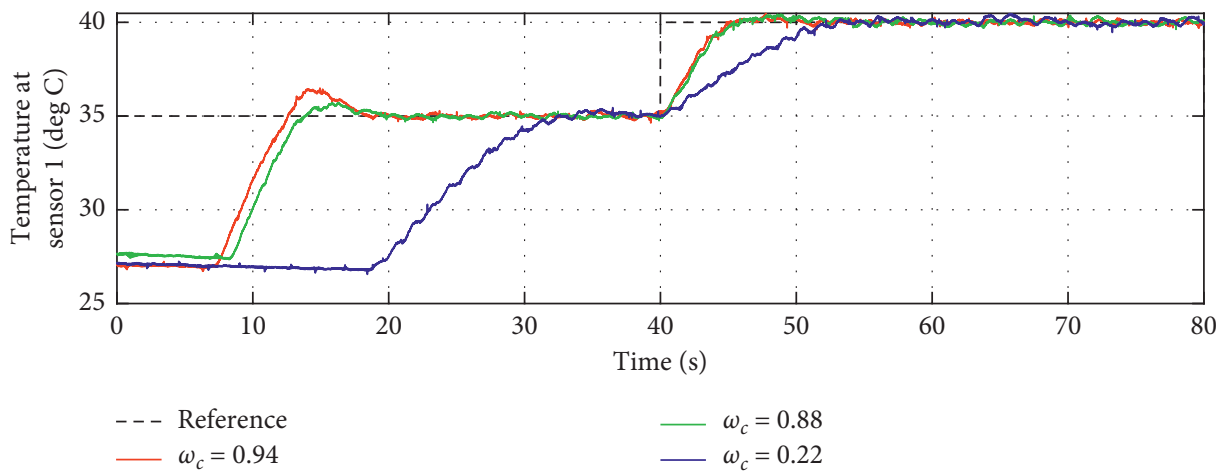

(a)
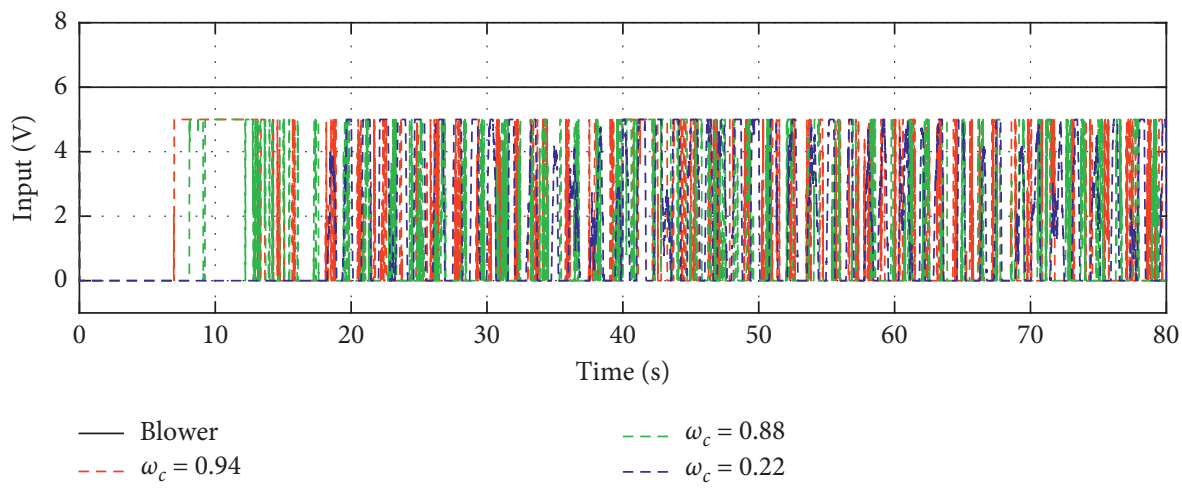

(b)

FIGURE 5: Experimental results with integer order LADRC controller ( $\omega_{c}$, variation of closed-loop pole position).



(a)

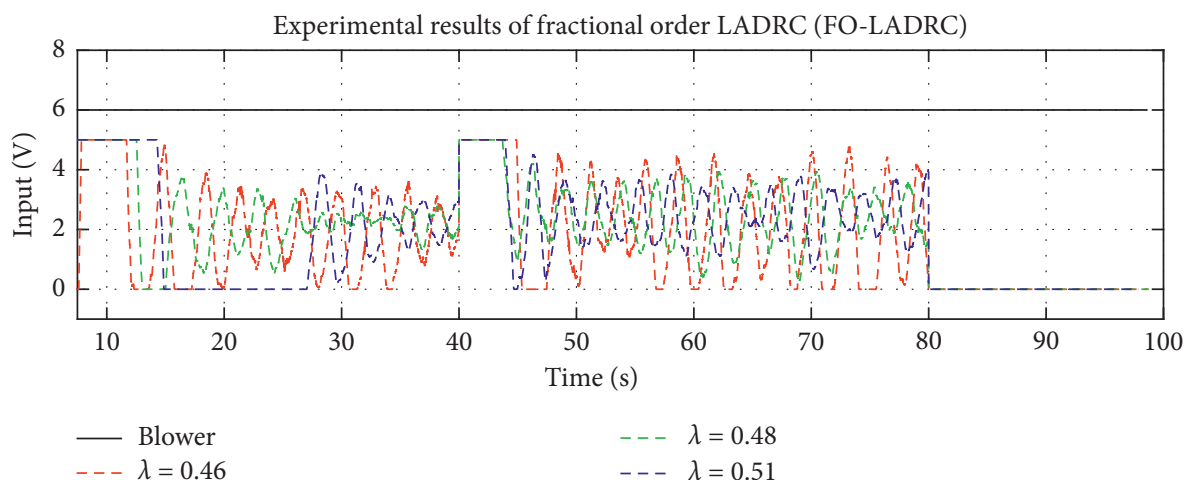

(b)

FIgURE 6: Experimental results with fractional order LADRC (FO-LADRC) controller, for different values of $\lambda$. 


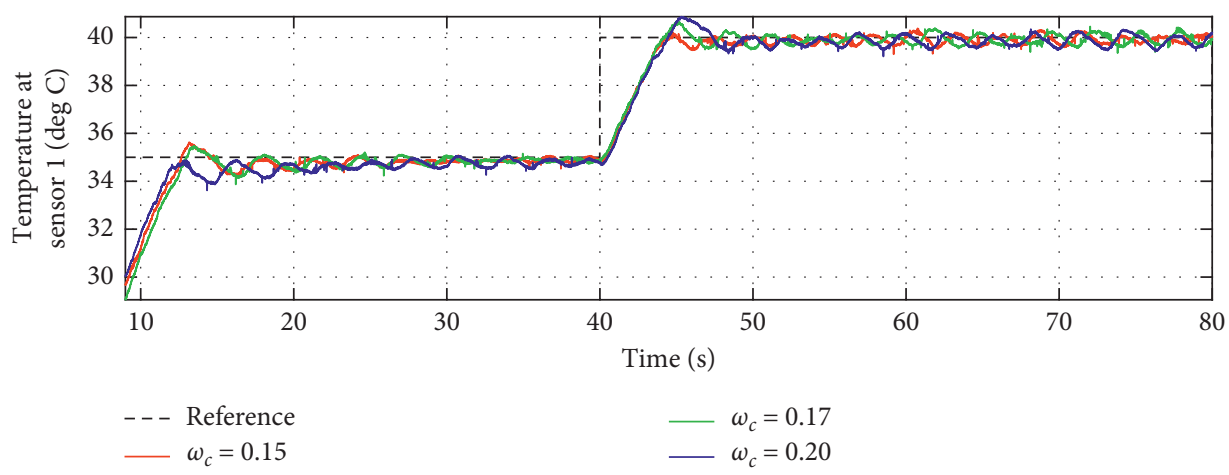

(a)

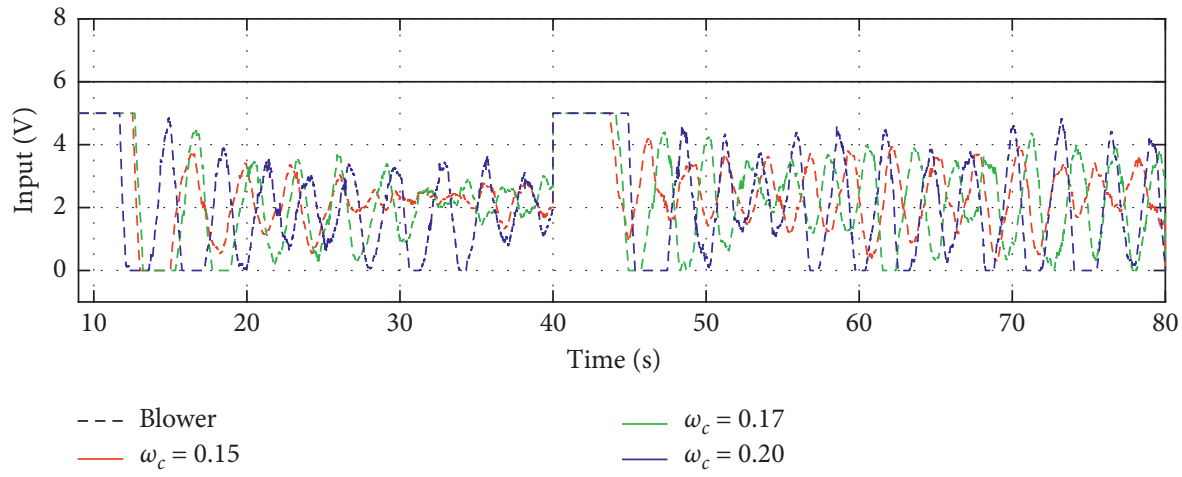

(b)

FIGURE 7: Experimental results with fractional order LADRC (FO-LADRC) controller, for different values of closed-loop pole position.

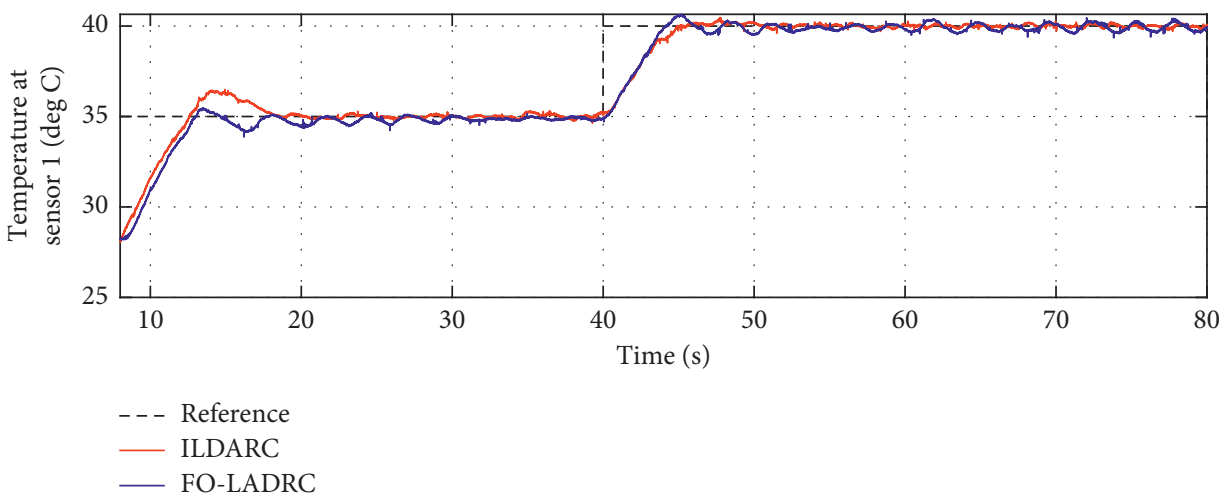

(a)

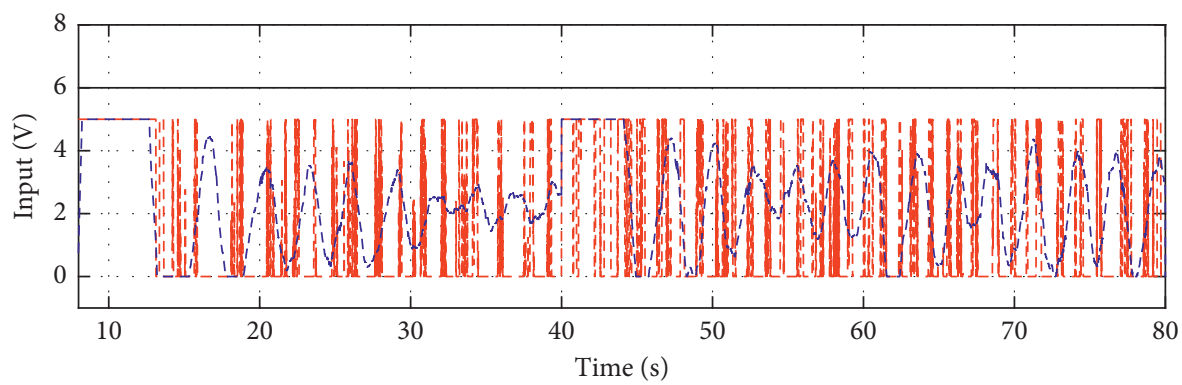

- Blower
$-\ldots$ ILDARC
- - FO-LADRC

(b)

Figure 8: Experimental comparison between ILADRC and FO-LADRC for sensor 1. 
TABle 1: Performance comparison of the three experiments using FO-LADRC.

\begin{tabular}{lcc}
\hline Experiment & $\lambda$ & $\omega_{c}$ \\
\hline No. 1 & 0.46 & 0.2 \\
No. 2 & 0.48 & 0.15 \\
No. 3 & 0.51 & 0.15 \\
\hline
\end{tabular}
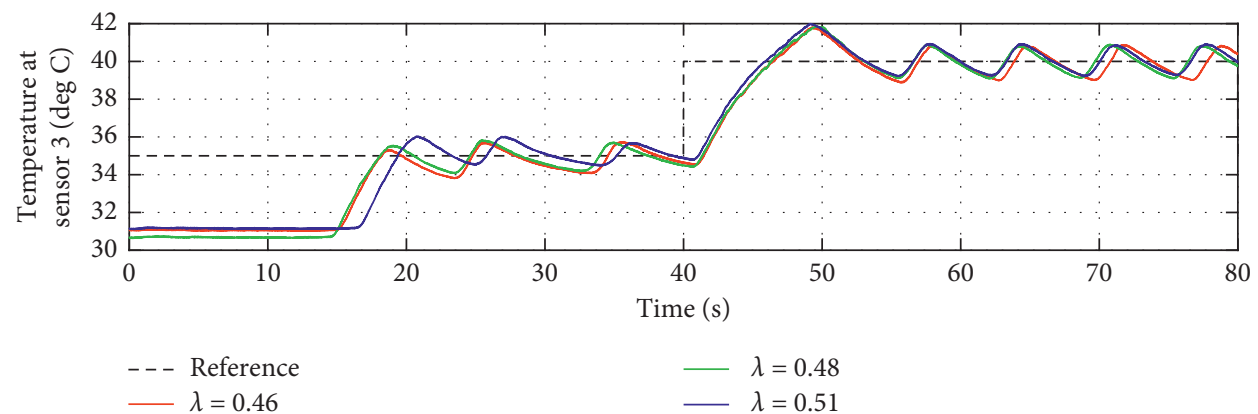

(a)

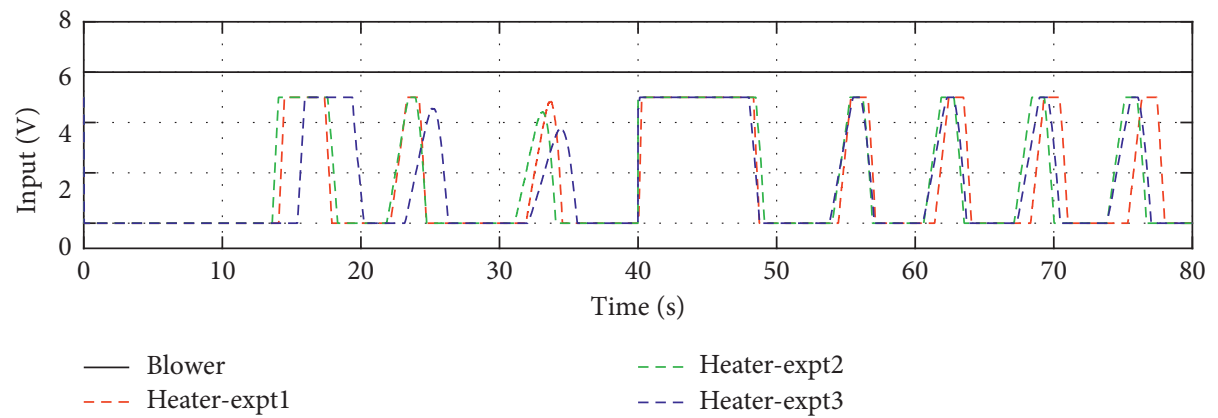

(b)

FIGURE 9: Robustness of FO-LADRC controller implemented for sensor 3: observation for different values of $\lambda$.

for three values from $\lambda(\lambda=0.46, \lambda=0.48$, and $\lambda=0.51)$. Result shows the best values for $\lambda=0.48$.

\section{Conclusion}

The aim of this research work is to represent a new fractional order-based LADRC scheme which is a model free analytical design technique. The robustness improvement and tracking results of the proposed technique are confirmed through an experiment on a heat-flow system. Because the heat-flow experiment platform is a delayed system, several tests have been carried out to study performances of the proposed controller and their robustness. All those tests have shown the comparatively better performance of the fractional order LADRC controller than the integer order LADRC controller.

\section{Data Availability}

No data were used to support this study.

\section{Conflicts of Interest}

The authors declare that they have no known conflicts of interest or personal relationships that could have appeared to influence the work reported in this paper.

\section{Acknowledgments}

This project was funded by the Deanship of Scientific Research (DSR), King Abdulaziz University, Jeddah, Saudi Arabia, under grant no. KEP-Msc-36-135-38. The authors, therefore, acknowledge with thanks the DSR technical and financial support.

\section{References}

[1] J. Han, "From pid to active disturbance rejection control," IEEE Transactions on Industrial Electronics, vol. 56, pp. 900906, 2009.

[2] J. Yang, H. Cui, S. Li, and A. Zolotas, "Optimized active disturbance rejection control for dc-dc buck converters with uncertainties using a reduced-order gpi observer," IEEE Transactions on Circuits and Systems-I, vol. 65, no. 2, pp. 832-841, 2018.

[3] L. Sun, J. Dong, D. Li, and K. Y. Lee, “A practical multivariable control approach based on inverted decou-pling and decentralized active disturbance rejection controller," Industrial and Engineering Chemistry Research, vol. 55, pp. 2008-2019, 2016.

[4] S. Das, S. Saha, S. Das, and A. Gupta, "On the selection of tuning methodology of FOPID controllers for the control of 
higher order processes," ISA Transactions, vol. 50, no. 3, pp. 376-388, 2011.

[5] C. A. Monje, B. M. Vinagre, V. Feliu, and Y. Chen, "Tuning and auto-tuning of fractional order controllers for industry applications," Control Engineering Practice, vol. 16, no. 7, pp. 798-812, 2008.

[6] U. M. Al-Saggaf, I. M. Mehedi, R. Mansouri, and M. Bettayeb, "State feedback with fractional integral control design based on the bode's ideal transfer function," International Journal of Systems Science, vol. 47, no. 1, pp. 149-161, 2016.

[7] U. M. Al-Saggaf, I. M. Mehedi, R. Mansouri, and M. Bettayeb, "Rotary flexible joint control by fractional order controllers," International Journal of Control, Automation and Systems, vol. 15, no. 6, pp. 2561-2569, 2017.

[8] M. Bettayeb, R. Mansouri, U. Al-Saggaf, and I. M. Mehedi, "Smith predictor based fractional-order-filter pid controllers design for long time delay systems," Asian Journal of Control, vol. 19, no. 2, pp. 587-598, 2017.

[9] I. Clara, Y. Zhou, and J. A. Tenreiro Machado, "Special issue: advances in fractional dynamics and control," Journal of Vibration and Control, vol. 22, no. 8, pp. 1969-1971, 2016.

[10] H. N. Farzaneh, F. Ali, G. Zadeh Hossein, F. M. Hassan, and H. N. S. Hassan, "Precise tip-positioning control of a singlelink flexible arm using a fractional-order sliding mode controller," Journal of Vibration and Control, vol. 26, no. 1, pp. 19-20, 2020.

[11] I. M. Mehedi, "State feedback based fractional order control scheme for linear servo cart system," Journal of Vibroengineering, vol. 20, no. 1, pp. 782-792, 2018.

[12] I. M. Mehedi, U. M. Al-Saggaf, R. Mansouri, and M. Bettayeb, "Two degrees of freedom fractional controller design: application to the ball and beam system," Measurement, vol. 135, pp. 13-22, 2019.

[13] Q. Quanser, Innovative Edutech- Heat Flow Experiment: User Manual, Quanser Inc., Markham, Canada, 2009.

[14] Q. Quanser, Innovative Edutech- Heat Flow Laboratory, Quanser Inc., Markham, Canada, 2012.

[15] M. Bettayeb and R. Mansouri, "Imc-pid-fractional-orderfilter controllers design for integer order systems," ISA Transactions, vol. 53, no. 5, pp. 1620-1628, 2014.

[16] M. Bettayeb and R. Mansouri, "Fractional imc-pid-filter controllers design for non integer order systems," Journal of Process Control, vol. 24, no. 4, pp. 261-271, 2014.

[17] A. Oustaloup, La Derivation Non Entiere: Thorie, Synthese et Applications, Hermes Science Publication, Stanmore, UK, 1995.

[18] H. W. Bode, Network Analysis and Feedback Amplifier Design, Federal Telecommunications Laboratories, Van Nostrand, New York, NY, UK, 1945.

[19] U. M. Al-Saggaf, I. M. Mehedi, M. Bettayeb, and R. Mansouri, "Fractional-order controller design for a heat flow process," Proceedings of the Institution of Mechanical Engineers, Part I: Journal of Systems and Control Engineering, vol. 230, no. 7, pp. 680-691, 2016.

[20] J. J. Carreño-Zagarra, J. L. Guzmán, J. C. Moreno, and R. Villamizar, "Linear active disturbance rejection control for a raceway photobioreactor," Control Engineering Practice, vol. 85, pp. 271-279, 2019.

[21] Y. Liu, J. Liu, and S. Zhou, "Linear active disturbance rejection control for pressurized water reactor power based on partial feedback linearization," Annals of Nuclear Energy, vol. 137, 2020.
[22] W. Tan and C. Fu, "Linear active disturbance-rejection control: analysis and tuning via imc," IEEE Transactions on Industrial Electronics, vol. 63, no. 4, pp. 2350-2359, 2015.

[23] Z. Gao, "Scaling and bandwidth-parameterization based controller tuning," in Proceedings of the 2003 American Control Conference, pp. 4989-4996, Denver, CO, USA, June 2003.

[24] D. Matignon, "Stability properties for generalized fractional differential systems," ESAIM: Proceedings, vol. 5, pp. 145-158, 1998. 